\title{
Determining the Boundary and Probability of Surface Urban Heat Island Footprint Based on a Logistic Model
}

\author{
Zhi Qiao ${ }^{1}\left(\right.$, , Chen $W^{1}{ }^{1}$, Dongqi Zhao ${ }^{2}$, Xinliang Xu ${ }^{3} \oplus$, Jilin Yang ${ }^{4,5}$, Li Feng ${ }^{6, *}$, \\ Zongyao Sun ${ }^{2}$ and Luo Liu ${ }^{7}$ \\ 1 Key Laboratory of Indoor Air Environment Quality Control, School of Environmental Science \\ and Engineering, Tianjin University, Tianjin 300350, China; qiaozhi@tju.edu.cn (Z.Q.); \\ wuc94@tju.edu.cn (C.W.) \\ 2 School of Architecture, Tianjin University, Tianjin 300272, China; dongqi_zhao@tju.edu.cn (D.Z.); \\ sun_zongyao@tju.edu.cn (Z.S.) \\ 3 State Key Laboratory of Resources and Environmental Information Systems, Institute of Geographical \\ Sciences and Natural Resources Research, Chinese Academy of Sciences, Beijing 100101, China; \\ xuxl@lreis.ac.cn \\ 4 Key Laboratory of Land Surface Pattern and Simulation, Institute of Geographic Sciences and Natural \\ Resources Research, Chinese Academy of Sciences, Beijing 100101, China; yangjl.17b@igsnrr.ac.cn \\ 5 University of Chinese Academy of Sciences, Beijing 100049, China \\ 6 School of Geographic Science and Engineering, Hohai University, Nanjing 211100, China \\ 7 Guangdong Province Key Laboratory for Land Use and Consolidation, The College of Natural Resources \\ and Environment, South China Agricultural University, Guangzhou 510642, China; liuluo@ou.edu \\ * Correspondence: fly@hhu.edu.cn; Tel.: +86-25-83787234
}

Received: 17 April 2019; Accepted: 3 June 2019; Published: 6 June 2019

\begin{abstract}
Studies of the spatial extent of surface urban heat island (SUHI or UHI Surf) effects require precise determination of the footprint (FP) boundary. Currently available methods overestimate or underestimate the SUHI FP boundary, and can even alter its morphology, due to theoretical limitations on the ability of their algorithms to accurately determine the impacts of the shape, topography, and landscape heterogeneity of the city. The key to determining the FP boundary is identifying background temperatures in reference rural regions. Due to the instability of remote sensing data, these background temperatures should be determined automatically rather than manually, to eliminate artificial bias. To address this need, we developed an algorithm that adequately represents the decay of land surface temperature (LST) from the urban center to surrounding rural regions, and automatically calculates thresholds for reference rural LSTs in all directions based on a logistic curve. In this study, we applied this algorithm with data from the Aqua Moderate Resolution Imaging Spectroradiometer (Aqua/MODIS) 8-day level 3 (L3) LST global grid product to delineate precise SUHI FPs for the Beijing metropolitan area during the summers of 2004-2018 and determine the interannual and diurnal variations in FP boundaries and their relationship with SUHI intensity.
\end{abstract}

Keywords: surface urban heat island; footprint; threshold; boundary; logistic model; MODIS

\section{Introduction}

Urbanization results in land use change from non-urban to urban land, and is accompanied by increases in anthropogenic heat release [1-3]. Consequently, city energy and water balances are altered through the reduction of latent heat flux and the rise in sensible heat flux, which further affect regional and even global climates [4-7]. Among these impacts, the urban heat island (UHI), a phenomenon 
characterized by significantly higher air and land surface temperatures (LSTs) in urban areas than in suburban areas, negatively affects the health and comfort of urban dwellers and greatly increases energy consumption [8-12]. The UHI can be divided into four types, subsurface urban heat island $\left(\mathrm{UHI}_{\mathrm{Sub}}\right)$, surface urban heat island (SUHI), canopy layer urban heat island $\left(\mathrm{UHI}_{\mathrm{UCL}}\right)$, and boundary layer urban heat island ( $\mathrm{UHI}_{\mathrm{UBL}}$ ), according to temperature differences in urban and rural cooling and warming rates at the surface, in the substrate and in the air [13]. In general, SUHI for cities or regions is easily estimated by means of satellite and aircraft sensors, which could be used to retrieve the differences between the interface of the outdoor atmosphere with the solid materials of the city and equivalent rural air to ground interface [13]. More importantly, the area affected by a SUHI is much larger than the area of the city [14-17]. Therefore, SUHI has gained considerable research interest during the past several decades [18-24].

UHI intensity (UHII), a well-known indicator of SUHI, is calculated as the temperature difference between urban land and a reference rural region [14,25-32]. Although UHII quantitative and spatiotemporal characteristics, as well as SUHI sources/sinks [8,33-35], have been characterized for many cities worldwide using multiple algorithms [14,25-32], in-situ station observations [36-40], and remote sensing techniques [41], the results of these studies lack stability and generalizability. The magnitude and extent of the SUHI can be biased by the selected reference rural regions, including a few specific observation stations or pixels, one or several types of land use, all areas within the buffer at a certain distance from the city boundary, etc. [42,43]. Therefore, accurate quantification of SUHI requires the selection of appropriate reference rural regions and relevant temperature thresholds for these regions.

The footprint (FP) of the UHI effect is a relatively new index that quantifies the area affected by the SUHI, by defining the extent of increased temperature with respect to the reference rural region [17,44-47]. This comprehensive index considers both the magnitude and spatial extent of the SUHI effect $[17,46]$. Gaussian surface models have been widely applied to calculate the FP due to its good performance in SUHI modeling [46,48-50]. A single exponential decay model has also been used to extract the FP by examining obvious urban/rural temperature "cliffs" [17]. In these previous studies, topographical factors and the SUHI sink (e.g., water or green land) were determined to eliminate the effects of abnormally low-temperature objects on the SUHI [35,51]. However, most studies have adopted the shape of the city as a default basis for the SUHI FP, with buffer zones being stretched from the border of the urban area [17]. These approaches appear not to have accounted for differences in the effects of land use types or landscape heterogeneity on LSTs outside of the urban area, and can impact the SUHI FP extent in multiple directions [52-56]. Therefore, the objective of this study was to develop a new method to determine LSTs threshold for reference rural regions in all directions, with the aim of determining a more precise boundary of the SUHI FP in a metropolitan region. The proposed new method will be more reasonable than previous methods in that it minimizes the effects of the city's shape, topography, or landscape heterogeneity.

\section{Materials and Methods}

\subsection{Study Area}

The study area is the Beijing metropolitan region, China (Figure 1). This metropolitan region was selected for several reasons. The city has a sub-humid warm temperate continental monsoon climate and four distinct seasons, with a hot and humid summer. The phenomenon that there is an obvious summer SUHI intensity in Beijing has been widely observed through multi-source remote sensing data [35]. Meng et al. pointed out that the maximum value of the mean SUHI intensity can reach $5.88^{\circ} \mathrm{C}$ and $2.46^{\circ} \mathrm{C}$ in day and night, respectively, during 2003-2015 [57]. Mountains and plains are distributed to the northwest and southeast of Beijing, respectively, which is important for eliminating the effects of terrain on the SUHI FP and validating the proposed method. 


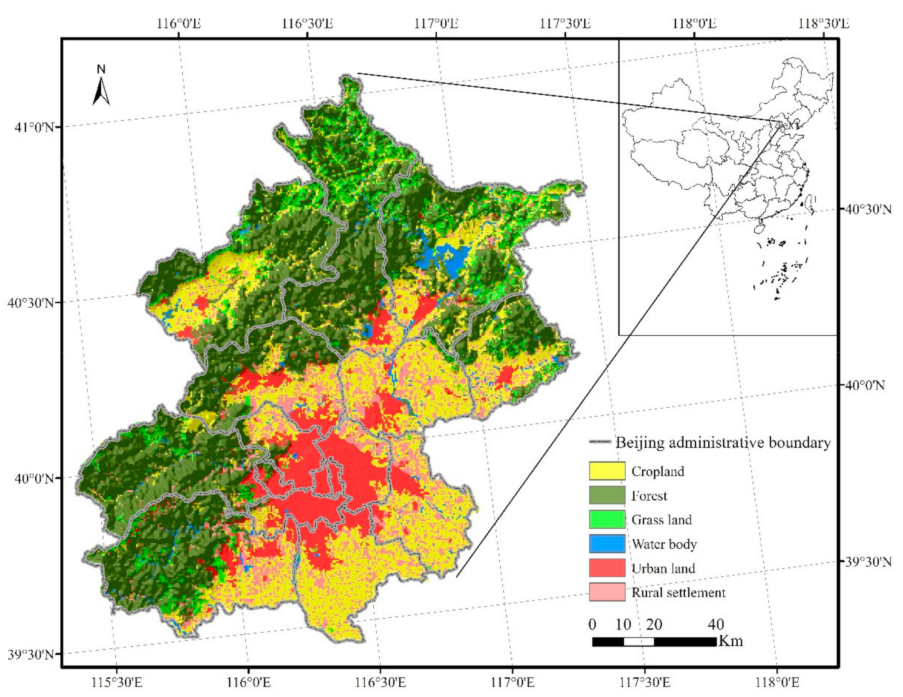

Figure 1. Location of the study area and land use types in Beijing metropolitan region (2015).

\subsection{Data Source}

The moderate resolution imaging spectroradiometer (MODIS), which has fine spatiotemporal resolution and data accuracy, is widely used in the study and simulation of SUHI processes and mechanisms [11,12,35,58]. In this study, we used the Aqua MODIS 8-day level 3 (L3) LST global product (MYD11A2), which has a spatial resolution of $1 \mathrm{~km}$, for the summers of 2004-2018 (June, July, and August). Its overpass times are around 13:30 (local solar time) in descending mode and 1:30 in ascending mode, representing daytime and nighttime LST observations, respectively. The dataset includes 12 data periods per year. Each period can be further divided into daytime and nighttime LST. The attached quality control (QC) files were used to exclude low-quality pixel values affected by clouds or other noise.

Land use datasets were used to remove pixel values affected by cold sources (e.g., ponds, lakes, rivers, parks, or golf courses) in urban areas. The 30-m-resolution dataset of the period of 2005 and 2015 was manually interpreted via Landsat Thematic Mapper (TM)/Enhanced Thematic Mapper (ETM) images at the Chinese Academy of Sciences and was found to have high classification accuracy based on massive field sampling [59]. The Beijing metropolitan region comprises six types of land use, including cropland, forest, grassland, water, urban land, and rural settlement in the dataset. The land use of 2017 with 10-m-resolution comes from Finer Resolution Observation and Monitoring of Global Land Cover (http://data.ess.tsinghua.edu.cn/fromglc2017v1.html) [60]. The dataset includes cropland, forest, grassland, shrubland, wetland, water, impervious surface, and bare land in the Beijing metropolitan region.

A digital elevation model (DEM) with a spatial resolution of approximately $90 \mathrm{~m}$ was downloaded from the Space Shuttle Radar and Topography Mission (SRTM) and used to take into account terrain effects [12].

\subsection{Method}

To quantify UHII, we first defined the reference rural LST background field. The LST background field must be relatively stable and unaffected by the urban area. However, depending on the topography and landscape heterogeneity, the selection of different reference points can result in different LST background fields and SUHI intensity values [37]. We assumed different reference points for different directions, setting the urban center (or center of gravity) as the polar coordinate origin. Thus, the LST 
of each pixel and the reference rural LST in a certain direction can be expressed as $\mathrm{T}_{S}(\theta, \mathrm{r})$ and $\mathrm{T}_{r e f}(\theta)$. The UHII for each pixel, noted as UHII $(\theta, r)$, can thus be calculated as follows.

$$
\operatorname{UHII}(\theta, \mathrm{r})=\mathrm{T}_{S}(\theta, \mathrm{r})-\mathrm{T}_{r e f}(\theta)
$$

We first determined the center (or center of gravity) of the study area. Buffer rings were then drawn from the urban center to the surrounding rural region (Figure 2).

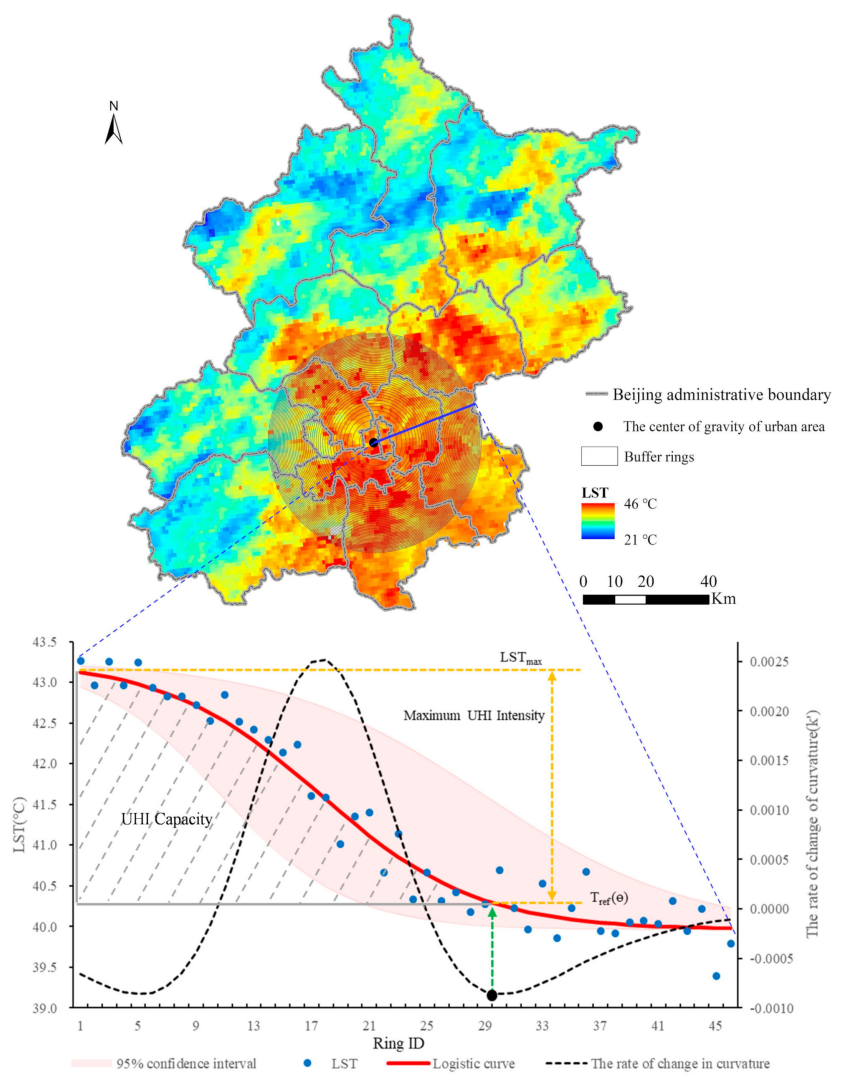

Figure 2. Buffer rings, land surface temperature (LST), and a schematic showing how reference rural LST is calculated using the logistic model (daytime, 26 June 2018).

To ensure equal sampling, we used buffer rings of equal area. In repeated experiments, the initial radius $r_{1}$ was set to $5 \mathrm{~km}$, with each subsequent ring area $S_{i}$ equal to the initial ring area $S_{1}$. Thus, the radius $r_{i}$ of each subsequent ring was determined as $5 \sqrt{i} \mathrm{~km}$, where $i$ is the number of the buffer ring. The average LST within each buffer ring was then calculated as follows.

$$
\overline{\mathrm{T}_{S}}(\mathrm{r})=\frac{1}{2 \pi} \int_{0}^{2 \pi} \mathrm{T}_{S}(\theta, \mathrm{r}) \mathrm{d} \theta
$$

Theoretically, the air temperature should follow a relatively well-defined spatial pattern radiating from the urban center to the suburbs [17,47]. Although the LST would show a certain fluctuation because of the surface properties, including geometric, radiative, thermal, moisture and aerodynamic, during the radiation process (see the blue points in Figure 2), the overall performance of the fitted logistic curve (see the red line in Figure 2) could reflect the similar decline trend compared to air temperature [61-63]. When these regions are far enough away from the urban center, the LST should remain relatively stable as it is no longer affected by the SUHI effect. During the process of LST decline, abnormal values can occur when LST is affected by topography, small cold sources (e.g., ponds, 
lakes, rivers, parks, and golf courses), or clouds. An algorithm must be developed to eliminate these abnormal values prior to the fitting process.

$$
\overline{\mathrm{T}_{S}}(\mathrm{r})=\frac{1}{2 \pi} \int_{0}^{2 \pi} \mathrm{T}_{S}(\theta, \mathrm{r}) \cdot \mathrm{g}(\mathrm{DEM}, \text { water, greenland, cloud }) \mathrm{d} \theta,
$$

After the removal of outliers, the logistic model was finally applied to fit the $\mathrm{T}_{\text {ref }}(\theta)$ curve.

$$
\mathrm{T}_{r e f}(\theta)=f\left(\overline{\mathrm{T}_{S}}(\mathrm{r})\right)
$$

The blue points in Figure 2 indicate average LST values the buffer rings, extracted after the outlier removal. These LST points were fitted to the smoothed LST series curve (red solid line) using the logistic algorithm. This algorithm was applied to characterize the LST series using the most important transition point derived from the LST spatial series data, i.e., $\mathrm{T}_{r e f}(\theta)$, which is the location where the LST becomes relatively stable. The peripheral area at this location is no longer the SUHI FP.

The change in the LST data for a single urban structure can be modeled as follows:

$$
f(\overline{\mathrm{T} \prime S}(\mathrm{r}))=\frac{c}{1+e^{a+b r}}+\mathrm{d},
$$

where $\mathrm{r}$ is the buffer ring number, $f\left(\overline{\mathrm{T}_{S}}(\mathrm{r})\right)$ is the LST value at buffer ring $\mathrm{r}$, a and $\mathrm{b}$ are the parameters of the logistic curve that require fitting. The sum of $\mathrm{c}$ and $\mathrm{d}$ represents the highest LST value among all buffer rings, and $d$ is the lowest LST value among all buffer rings.

Mathematically, these transition points can be calculated using the rate of change of the curvature (K) curve (Figure 2, black dotted line) of the fitted LST series curve. Values of $K$ for Equation (5) at different buffer rings can be calculated as follows:

$$
K=\frac{d_{\beta}}{d_{s}}=-\frac{b^{2} c z(1-z)(1+z)^{3}}{\left[[1+z]^{4}+[b c z]^{2}\right]^{3 / 2}}
$$

where $z=e^{a+b r}, \beta$ is the angle of the unit tangent vector at buffer ring $r$ along a differentiable curve, and $s$ is the unit length of the curve. The $K^{\prime}$ value, which represents the rate of change of the curvature curve, can be calculated as follows.

$$
K^{\prime}=b^{3} \mathrm{cz}\left\{\frac{3 z\{1-z\}\{1+z\}^{3}\left[2[1+z]^{3}+b^{2} c^{2} z\right]}{\left[[1+z]^{4}+[b c z]^{2}\right]^{5 / 2}}-\frac{\{1+z\}^{2}\left\{1+2 z-5 z^{2}\right\}}{\left[[1+z]^{4}+[b c z]^{2}\right]^{3 / 2}}\right\}
$$

As the LST decreases from the urban area to the surrounding area, three extreme values of $K^{\prime}$ in the LST fitted curve can be inferred from Equation (7). The last minimum point (black) corresponds to the location of the reference rural region. $\mathrm{T}_{r e f}(\theta)$, the average LST in the reference ring, was identified as the reference rural LST, and the difference between the maximum LST and $\mathrm{T}_{\text {ref }}(\theta)$ is the UHII at an angle of $\theta$. Thus, each pixel can be considered part of the SUHI FP based on whether the LST in the pixel is greater than the threshold $\mathrm{T}_{\text {ref }}(\theta)$ (Figure 3). 


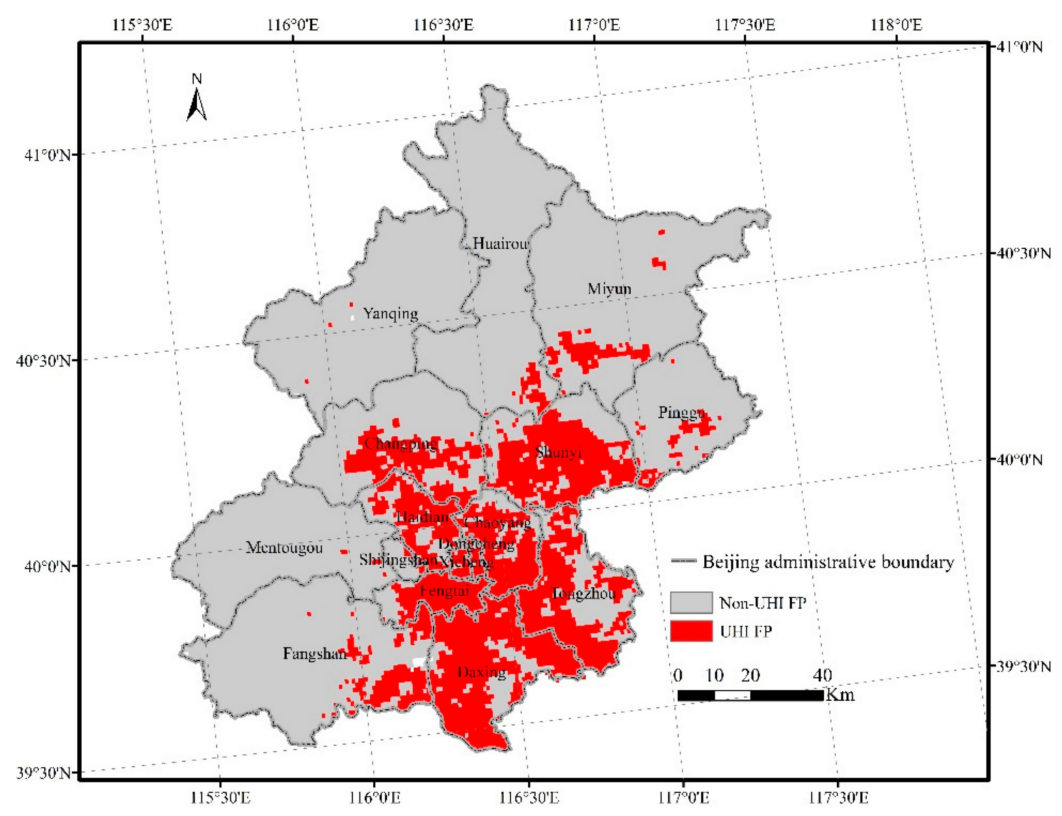

Figure 3. The boundary of surface urban heat island footprint (SUHI FP) in Beijing metropolitan region (daytime,26 June 2018).

To avoid the impact of remote sensing data instability, we further explored the probability of seasonal SUHI FP for each pixel via Equation (8), such that higher probability indicated a greater likelihood that the pixel was part of the SUHI FP during that season.

$$
\operatorname{Prob}_{F P}(\theta, \mathrm{r})=\frac{\operatorname{Num}_{F P}(\theta, \mathrm{r})}{\operatorname{Num} m_{\text {logistic }}(\theta, \mathrm{r})} \times 100 \%,
$$

where $\operatorname{Prob}_{F P}(\theta, \mathrm{r})$ means that the probability of seasonal SUHI FP for each pixel. $\operatorname{Num}_{F P}(\theta, \mathrm{r})$ means that the number of the pixel being judged as the SUHI FP in summer. Numlogistic $(\theta, r)$ means that the number of the pixel passed the significance test through the logistic fitting. For the 8-day MODIS LST product, the value of $N_{\text {um }}$ logistic $(\theta, r)$ should range between 0 and 12 . This probability was calculated only if the logistic fit was found to be significant within the 8-day MODIS LST product.

UHI capacity was introduced to characterize the degree of UHI effect in the UHI FP.

$$
C_{U H I}=\iint_{D} U H I I(\theta, r) d \sigma
$$

where $C_{U H I}$ is UHI capacity, i.e. the cumulative amount of UHII in the UHI FP (shown in the shaded part in Figure 2). The unit is ${ }^{\circ} \mathrm{C} \cdot \mathrm{km}^{2}$. D is the UHI FP area. UHII $(\theta, r)$ is the UHII in each pixel.

\section{Results}

\subsection{Spatiotemporal Variation in the FP}

\subsubsection{Daytime Spatiotemporal Variation in the FP}

Spatially, high-probability $(>70 \%)$ summer SUHI FPs were mainly concentrated in urban centers, including Dongcheng, Xicheng, Haidian, Chaoyang, Shijingshan, Fengtai Districts, the northern edge of Daxing District, and the Capital International Airport in Shunyi District (Figure 4). The summer SUHI FPs showed significant expansion between 2004 and 2018, especially from the northern edge to the center in Daxing District, from the southern edge to central Changping District, and outward 
from the Capital Airport. Even in the southern parts of Miyun and Huairou Districts, there were large patches of high-probability summer SUHI FPs in the last few years of the study period.
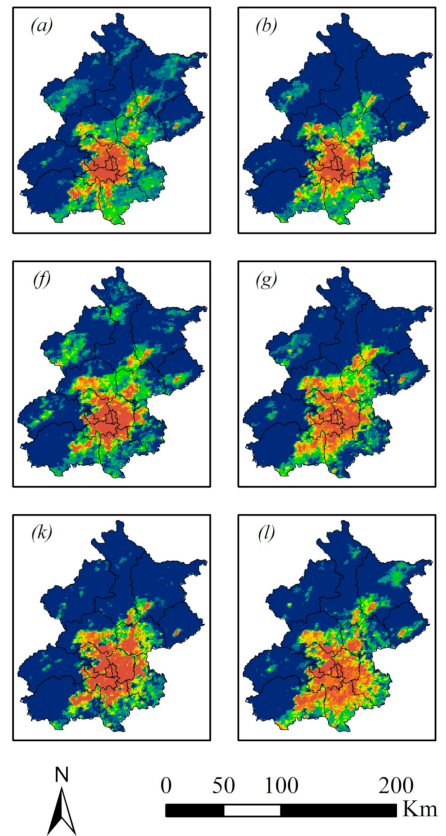
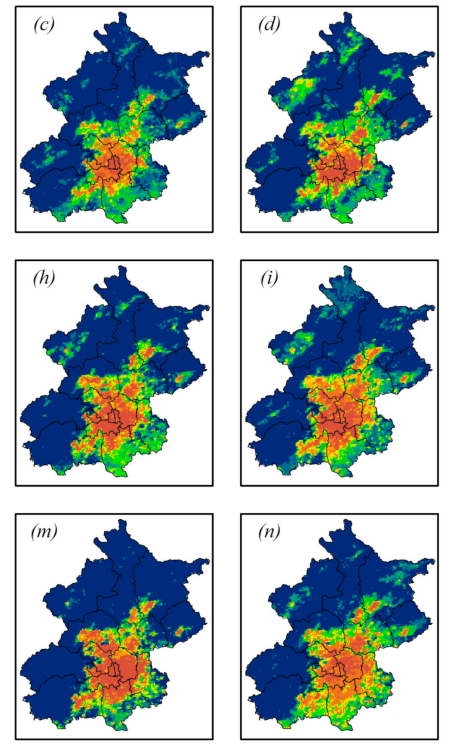

Beijing Administrative Boundary

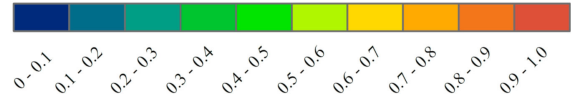

Figure 4. The spatial probability of summer SUHI FPs in daytime in Beijing metropolitan region. (a-e) 2004-2008, (f-j) 2009-2013, (k-o) 2014-2018.

Medium-probability (30-70\%) summer SUHI FPs were distributed at the periphery of the high-probability summer SUHI FPs, mainly concentrated in the eastern part of Fangshan District, the southwestern part of Daxing District, the central parts of Tongzhou and Changping Districts, the northern part of Shunyi District, and the southern parts of Miyun and Huairou Districts. Distinct expansion of medium-probability FPs was observed in the eastern part of Fangshan District, the southwestern part of Daxing District, and the southern part of Tongzhou District, and there were clear conversions from medium-probability to high-probability FPs in the central part of Changping District, the northern part of Shunyi District, and the southern parts of Miyun and Huairou Districts.

Low-probability $(<30 \%)$ summer SUHI FPs were mainly distributed in Yanqing, Huairou, Miyun, Pinggu, Mentougou, and Fangshan Districts at the periphery of the Beijing metropolitan area. There was no significant spatiotemporal evolution between 2004 and 2018.

Low-probability summer SUHI FPs had the largest area, followed by medium-probability and high-probability FPs (Figure 5). A 5.5:1:1 ratio was observed among the three types of FPs. Overall, low-probability SUHI FPs remained generally stable, accounting for approximately $72 \%$ of the total Beijing metropolitan area. The area of medium-probability FPs was basically the same as that of high-probability FPs, but with different trends during the period 2004-2018. The proportion of medium-probability SUHI FPs declined from a maximum of $18.96 \%$ in 2007 to a minimum of $9.85 \%$ in 2016. The proportion of high-probability SUHI FPs increased from a minimum of $9.64 \%$ in 2005 to a maximum of $18.77 \%$ in 2017 . These increases mainly resulted from the highest-probability $(>90 \%)$ SUHI FPs. These areas accounted for most of the high-probability SUHI FPs. 


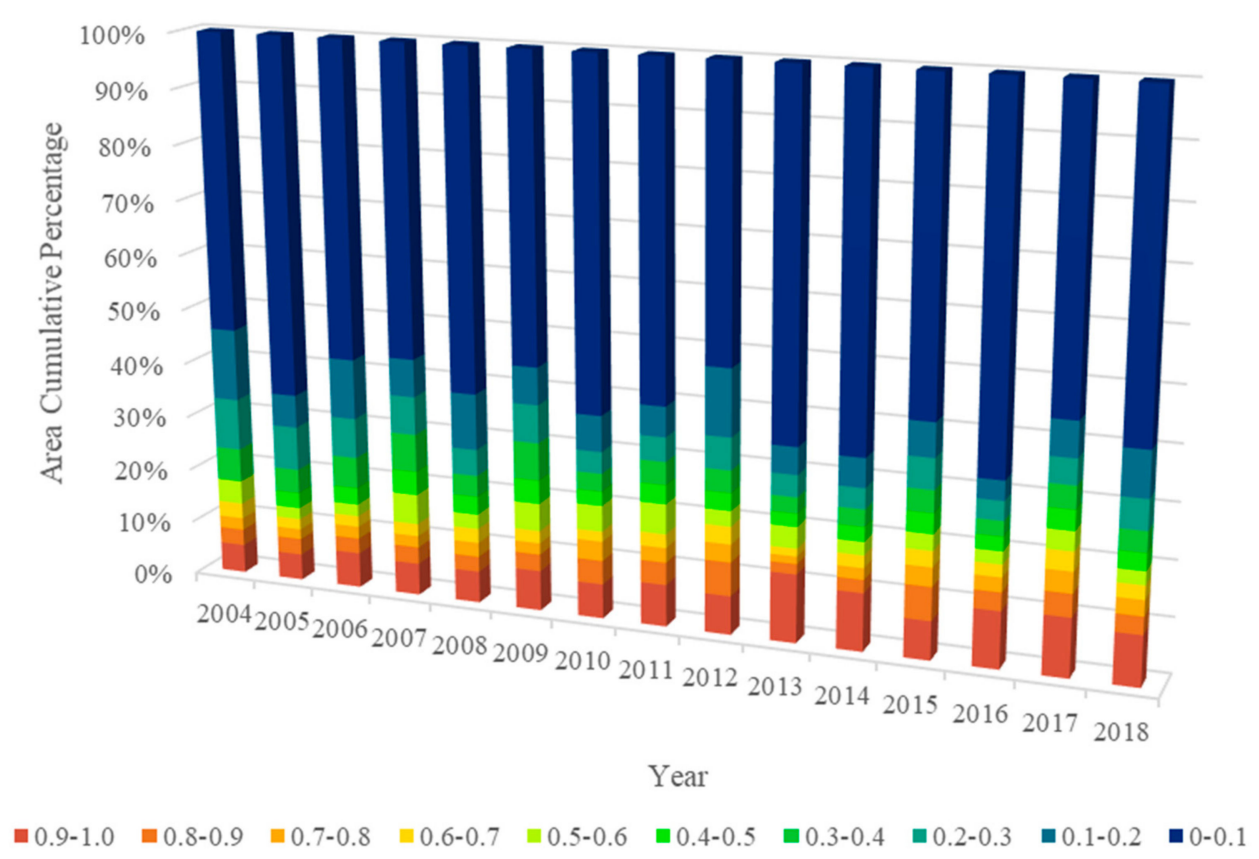

Figure 5. The area percentages of the different probabilities of summer SUHI FPs in daytime.

\subsubsection{Nighttime Spatiotemporal Variation in FPs}

Spatially, high-probability (>70\%) summer SUHI FPs were also concentrated in urban centers, including Dongcheng, Xicheng, Chaoyang, Shijingshan, and Fengtai Districts, the eastern part of Haidian District, the northeastern part of Fangshan District, and the northern part of Tongzhou District (Figure 6). The area of high-probability summer SUHI FPs was significantly smaller than that in the daytime. Notably, there were no high-probability summer SUHI FPs in the northern part of Daxing District or the northern and central parts of Haidian District. However, a large portion of the summer SUHI FPs appeared around the Miyun Reservoir in the nighttime. From 2004-2018, the nighttime high-probability summer SUHI FPs showed a weaker expansion trend than that in the daytime. There were four significant expansions of nighttime high-probability FPs. The largest of these was located in the northern part of Daxing District, with additional contiguous expansion between Fengtai and Fangshan Districts, and between Chaoyang District and the Capital International Airport in Shunyi District. Notably, high-probability summer SUHI FPs expanded around the Miyun Reservoir during the nighttime. 

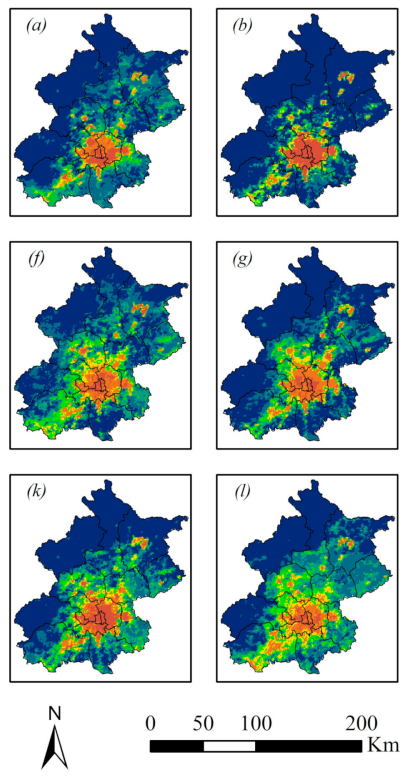
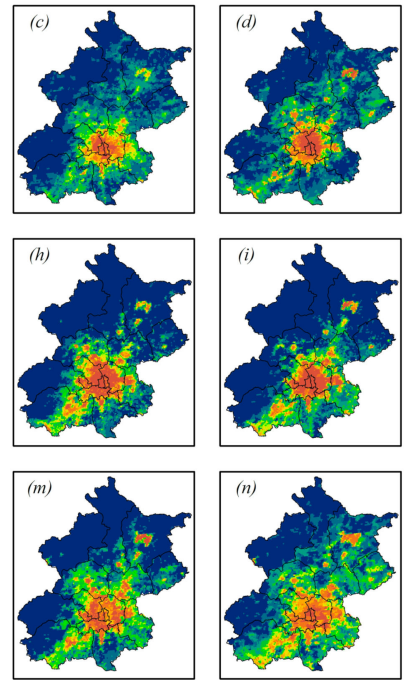

Beijing Administrative Boundary
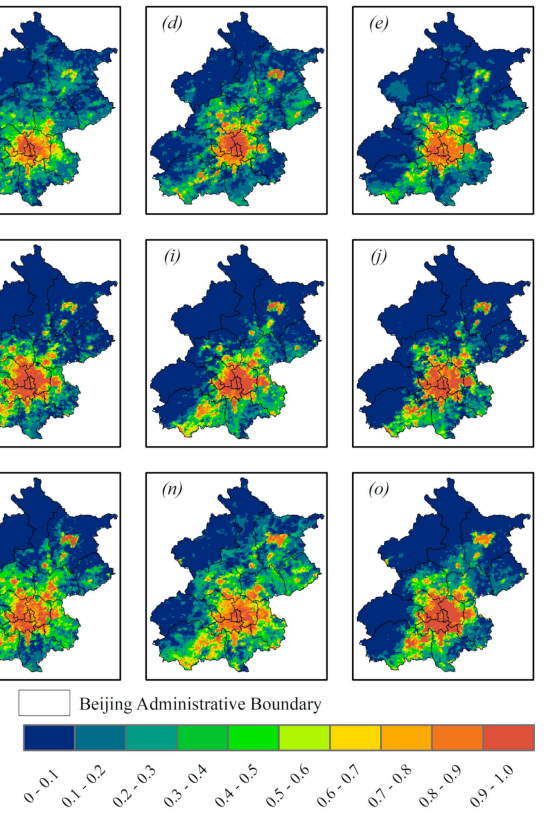

Figure 6. The spatial probability of summer SUHI FPs in nighttime in Beijing metropolitan region. (a-e) 2004-2008, (f-j) 2009-2013, (k-o) 2014-2018.

Medium-probability (30-70\%) summer SUHI FPs were also distributed at the outer periphery of the city, especially in the northern parts of Tongzhou and Daxing Districts near the urban area. There was also a large medium-probability summer SUHI FP in the central to the southern part of Fangshan District. From 2004-2018, medium-probability summer SUHI FPs showed the most significant expansion trend, even compared with the overall daytime trend. Medium-probability summer SUHI FPs sprawled rapidly to the south in Tongzhou, Daxing, and Fangshan Districts. There was also a contiguous northwestern expansion trend in Haidian and Changping Districts.

Low-probability $(<30 \%)$ summer SUHI FPs were the largest areas distributed far from the city center, with no significant spatiotemporal evolution except for an area encroached by medium-probability summer SUHI FPs between 2004 and 2018.

Nighttime low-probability SUHI FPs were larger than those in the daytime, accounting for $76.69 \%$ of the total Beijing metropolitan area during the study period, reaching $84.13 \%$ in 2005 (Figure 7). This result was mainly due to the decreased proportion of high-probability SUHI FPs compared to that in the daytime. The proportion of high-probability SUHI FPs was $9.80 \%$ between 2004 and 2018, 4.10\% less than that in the daytime. The proportion of medium-probability SUHI FPs was similar to that in the daytime. The area of medium-probability and high-probability SUHI FPs increased, whereas the area of low-probability SUHI FPs decreased from 2004-2018. The proportion of low-probability SUHI FPs declined from a maximum of $84.13 \%$ in 2005 to a minimum of $66.33 \%$ in 2017. This loss of area was mainly due to encroachment by medium-probability SUHI FPs, which increased in area from a minimum of $7.85 \%$ in 2005 to a maximum of $21.81 \%$ in 2017 . High-probability SUHI FPs showed a relatively stable growth trend. The highest-probability $(>90 \%)$ SUHI FPs accounted for most of the high-probability SUHI FPs. 


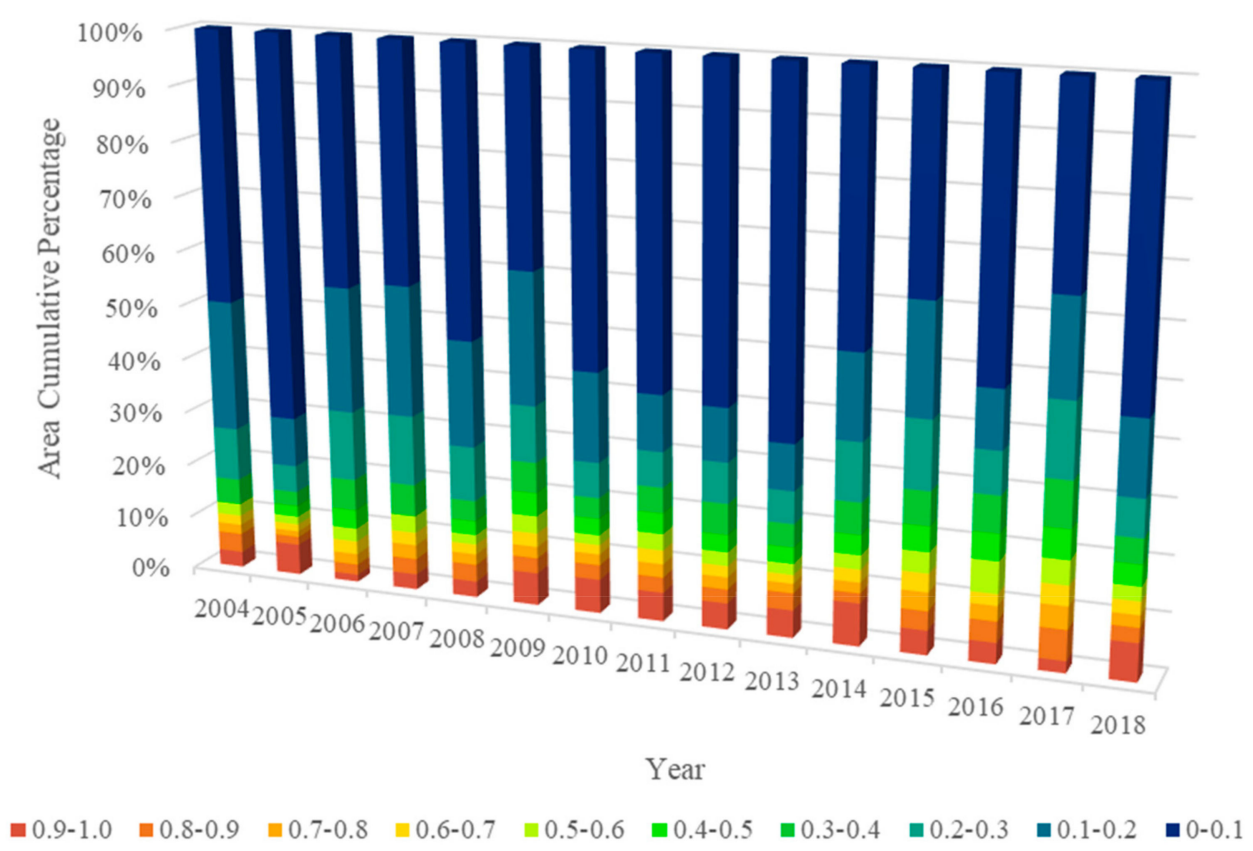

Figure 7. The area percentages of the different probabilities of summer SUHI FPs in nighttime.

\subsection{Comparative Analysis of SUHI FPs Obtained by Gaussian Surface Model and Logistic Model}

To validate the results from the proposed logistic method, we compared the derived UHI FPs with those calculated from the Gaussian surface model, which is the most commonly used method in the UHI FP literature [46]. Specifically, we used the 8-day SUHI FP in the summer of 2017 as an example of the comparative analysis.

Overall, the spatial patterns of SUHI FPs based on the two models are different, as all the SUHI FPs estimated by the Gaussian surface model were ovals that are continuous in space (Figure 8). For the Gaussian surface model, although the centers of the ovals appear to be near the city center, their morphological distributions greatly vary, as affected by the unstable LSTs retrieved from the remote sensing images. However, the SUHI FPs by the logistic method does not show such oval patterns.
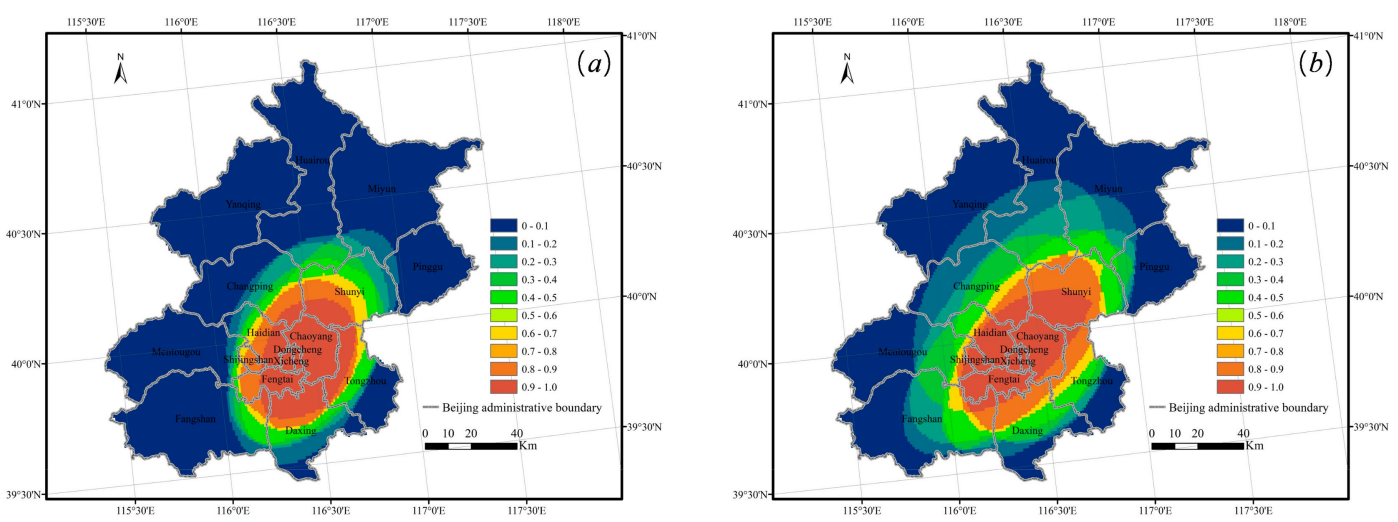

Figure 8. The spatial probabilities of SUHI FPs estimated by the Gaussian surface model in summer of 2017. (a) daytime, (b) nighttime.

Table 1 provides the areal percentages by the probability level of SUHI FP between the two methods. The areas of high-probability SUHI FPs estimated by the two models are almost identical in the daytime, accounting for $15.87 \%$ and $18.77 \%$ of the total area, respectively. In the nighttime, however, the proportion of high-probability SUHI FP by the Gaussian surface model (19.17\%) was significantly 
higher than that by the logistic model (11.86\%). Moving onto the medium probability, the areas of medium-probability SUHI FPs by the Gaussian surface model, for both daytime and nighttime, were substantially smaller than that by the logistic algorithm. In particular, the SUHI FP estimated by the Gaussian surface model in the daytime only accounted for $8.37 \%$ of the total study area, which was the smallest type of SUHI FP and was only half of the SUHI FP by the logistic algorithm. Last, for low probability, the nighttime SUHI FP areas by the two models are almost identical, accounting for $66.43 \%$ and $66.33 \%$ of the total area, respectively. However, in the daytime, the proportion of low-probability SUHI FP by the Gaussian surface model was $9.34 \%$ higher than the low-probability SUHI FP calculated by the logistic algorithm.

Table 1. The areas of the probability levels of SUHI FPs estimated by the Gaussian surface model and the logistic model (Unit: $\mathrm{km}^{2}$ ).

\begin{tabular}{ccccc}
\hline \multirow{2}{*}{ The Probability Levels of SUHI FPs } & \multicolumn{2}{c}{ Gaussian Surface Model } & \multicolumn{2}{c}{ Logistic Model } \\
\cline { 2 - 5 } & Daytime & Nighttime & Daytime & Nighttime \\
\hline $0.0-0.1$ & 9823 & 6723 & 8128 & 5180 \\
$0.1-0.2$ & 712 & 1678 & 934 & 2557 \\
$0.2-0.3$ & 567 & 1083 & 672 & 1983 \\
$0.3-0.4$ & 329 & 1014 & 614 & 1237 \\
$0.4-0.5$ & 436 & 683 & 523 & 772 \\
$0.5-0.6$ & 259 & 357 & 525 & 658 \\
$0.6-0.7$ & 202 & 307 & 508 & 529 \\
$0.7-0.8$ & 156 & 172 & 563 & 610 \\
$0.8-0.9$ & 166 & 256 & 612 & 808 \\
$0.9-1.0$ & 2004 & 2381 & 1575 & 320 \\
\hline
\end{tabular}

To further analyze the reasons for the differences in SUHI FPs between the Gaussian surface model and the logistic model, we calculated the area differences in different probability levels of SUHI FPs by cross-classification tables (Tables S1 and S2 in Supplementary Information).

In the daytime, among all the probability ranges, the SUHI FPs with the highest (0.9-1.0) and the lowest (0-0.1) have the highest agreement of recognition between the two models, with their agreement percentages reaching up to $80.51 \%$ and $64.60 \%$, respectively. However, for the other high-probability ranges, namely $0.8-0.9$ and $0.7-0.8$, only $6.21 \%$ and $3.20 \%$ of the SUHI FPs recognized by the logistic model were identified as the same level by the Gaussian surface model, with most being classified to the highest level (i.e., 0.9-1.0) by the latter due to the continuity of its shape.

In the nighttime, the distribution of SUHI FP probabilities was generally consistent with the that in the daytime. The agreement extent for the high-probability SUHI FPs between the two models is $74.91 \%$, while $14.67 \%$ of the logistic model were classified to low-probability by the Gaussian surface model. The agreement extent for the low-probability SUHI FPs between the two models is $80.06 \%$, while $6.94 \%$ of the logistic model were classified to low-probability by the Gaussian surface model.

We also analyzed the spatial differences of SUHI FPs between the two methods by overlaying different probability levels of SUHI FPs with land use maps (Tables S3-S6 in Supplementary Information). The major differences exist in cropland and impervious surface in the daytime, while in cropland, water bodies, and impervious surface at night. During the day, $11.46 \%, 24.55 \%$, and $63.99 \%$ of the impervious surface were identified as low-probability, medium-probability, and high-probability SUHI FPs estimated by the logistic algorithm, respectively. However, the proportion of the impervious surface with high-probability SUHI FPs estimated by the Gaussian surface model is 51.09\%, which is lower than that by the logistic model. During the day, 39.57\%, 33.26\%, and $27.17 \%$ of cropland were identified as low-probability, medium-probability, and high-probability SUHI FPs estimated by the logistic model. However, the proportion of the cropland being low-probability SUHI FPs estimated by the Gaussian surface model is $59.96 \%$, which is also higher than that by the logistic model. In fact, many cropland pixels have been proven to be a heat source for the city [35]. In the nighttime, the proportions of impervious surface with high-probability SUHI FPs estimated by the Gaussian surface model and the 
logistic algorithm are $55.34 \%$ and $40.67 \%$, respectively. Thus, the proportion of high-probability SUHI FPs estimated by the logistic algorithm in cropland was smaller than that estimated by the Gaussian surface model. However, the proportion of water bodies with high-probability SUHI FPs estimated by the logistic model reaches $59.62 \%$ at night, which is far higher than that by the Gaussian surface model. This is also consistent with the argument that the role of water could be a heat source for cities at night [35].

\subsection{Temporal Changes in UHII}

We first calculated the threshold LST value of the reference rural region for each 8-day MODIS LST product using Equation (4). Then, the UHII of each 8-day MODIS LST product was calculated using Equation (1), and the summer average maximum UHII value was calculated for all 8-day MODIS LST products for each year.

The average daytime maximum UHII was $4.27 \pm 0.52{ }^{\circ} \mathrm{C}$ in summer, and the average nighttime maximum UHII was $3.04 \pm 0.23^{\circ} \mathrm{C}$ (Figure 9). We further used the Mann-Kendall Test and homogeneity tests to determine whether the day and nighttime series of interannual maximum UHII between 2004 and 2018 has a monotonic upward or downward trend. Results show that both the day and night time series of interannual maximum UHII have an upward trend (Sen's slopes are 0.5048 and 0.0286 for the daytime and the nighttime, respectively). However, the upward trend for the daytime did not pass the $90 \%$ significance test, but the slight upward trend for the nighttime passed the $99 \%$ significance test. Radiation from the sun is the most important driver of climates near the ground [13]. In cities, urbanization, human-made structures and impervious surfaces replace vegetation, greenery, and water, altering radiation exchanges. The multi-faceted urban 'surface' that emits and reflects to itself can generate myriad distinct radiation budgets. These complex urban surfaces also absorb and store large amounts of solar shortwave radiation, while the reduction of sky-view factors decreases the loss of longwave radiation. In addition, cloud affects the transmission and emission of incoming radiation and increases the interception of outgoing radiation. Finally, air pollution may also affect the process of radiation exchanges [13].

To further understand the temporal changes of UHII, we calculated the summer average LSTs of high-probability SUHI FPs and the reference rural region between 2004 and 2018 (Figure 10).

There were increasing trends for the average LSTs of high-probability SUHI FPs and the reference rural region both in the daytime and in the nighttime. The extent of increase in the LST of the reference rural region was greater than that of the average temperature of SUHI FPs with the probability ranges of 0.8-0.9 and 0.9-1.0. The difference between day and night exists in terms of the level of significance of the increasing trend. The significant level for the daytime did not pass $90 \%$ significance test, but the significant level for the nighttime passed $90 \%$ significance test. These results explain why the UHII did not change significantly with the time between 2004 and 2018. 

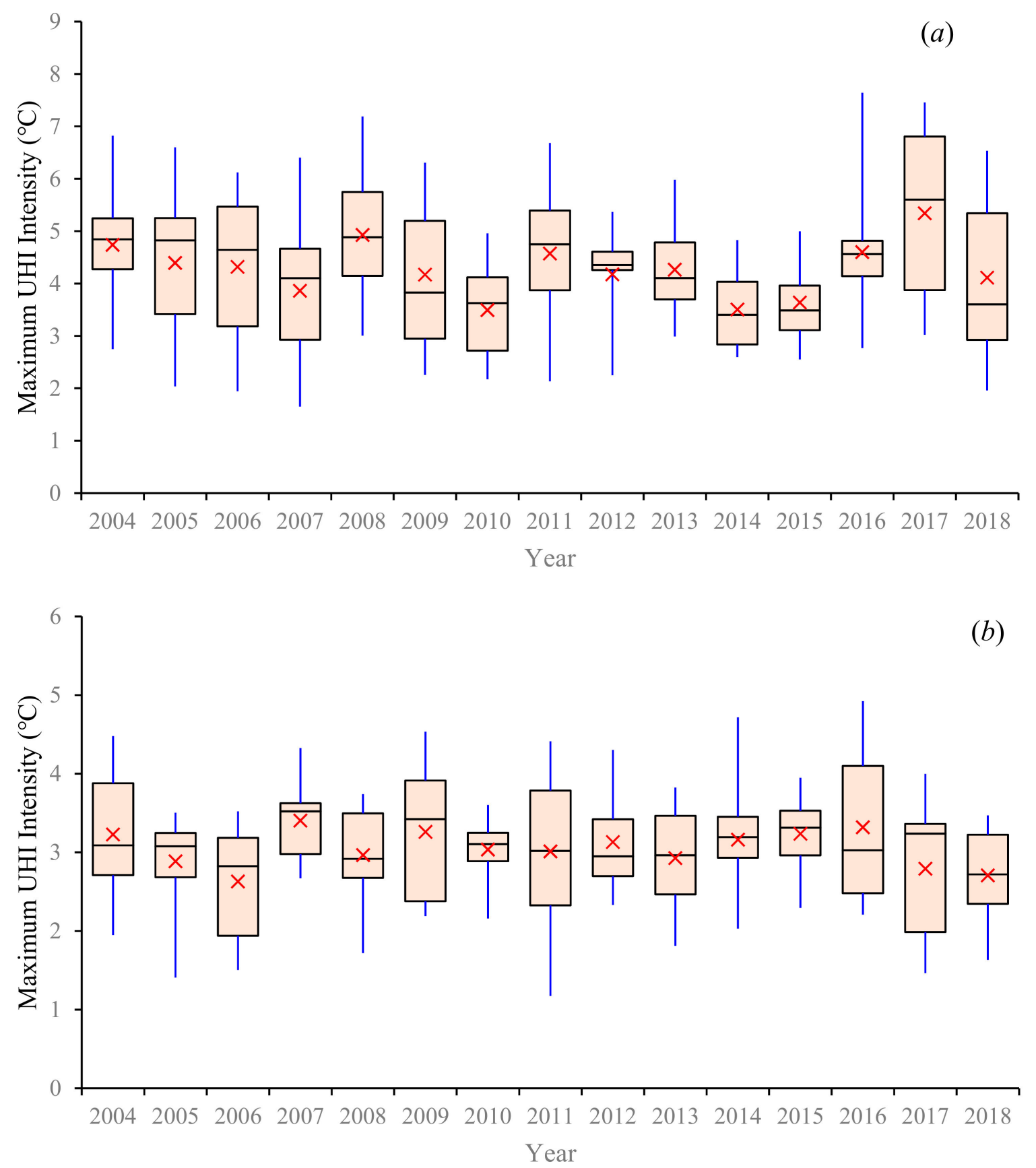

Figure 9. Temporal changes of the maximum urban heat island intensity (UHII) between 2004 and 2018. (a) daytime, (b) nighttime. 

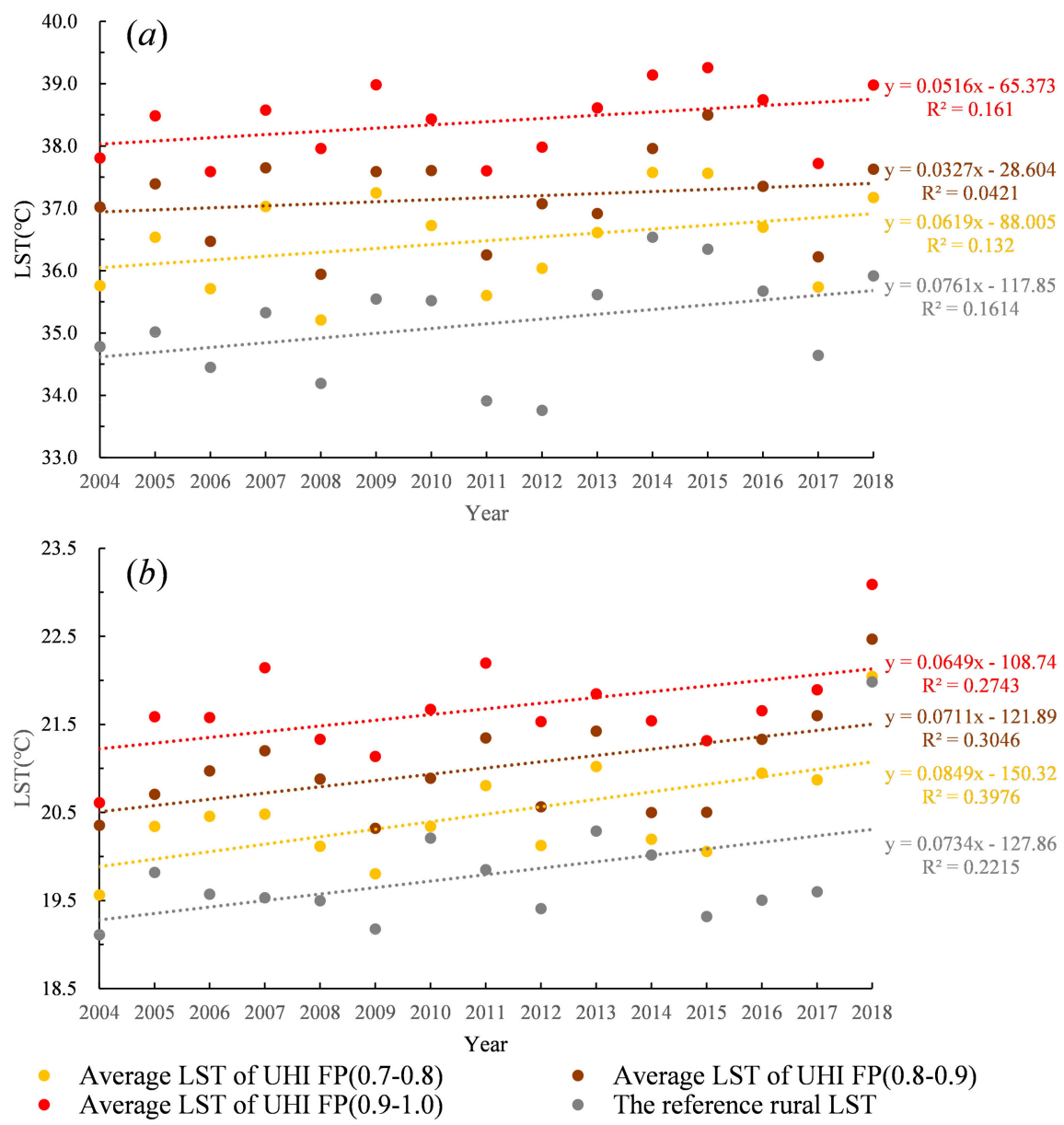

Figure 10. Temporal changes of the average LSTs of high-probability SUHI FPs and the reference rural region between 2004 and 2018. (a) daytime, (b) nighttime.

\subsection{Temporal Changes in UHI Capacity}

Compared to UHII, UHI capacities revealed more distinct temporal trends for different levels of UHI FPs. Generally, there were increasing trends for UHI capacities both in the daytime and in the nighttime between 2004 and 2018 (Figure 11). In particular, the UHI capacity of the SUHI FP with the highest probability range (0.9-1.0) has a more significantly increasing trend than the other two probability ranges. For example, in the daytime, the slope of the increasing trend for highest probability range is more than 15-27 times of those for the other two probability ranges, while in the nighttime, the growth rates are similar among the three high-probability UHI FPs. 


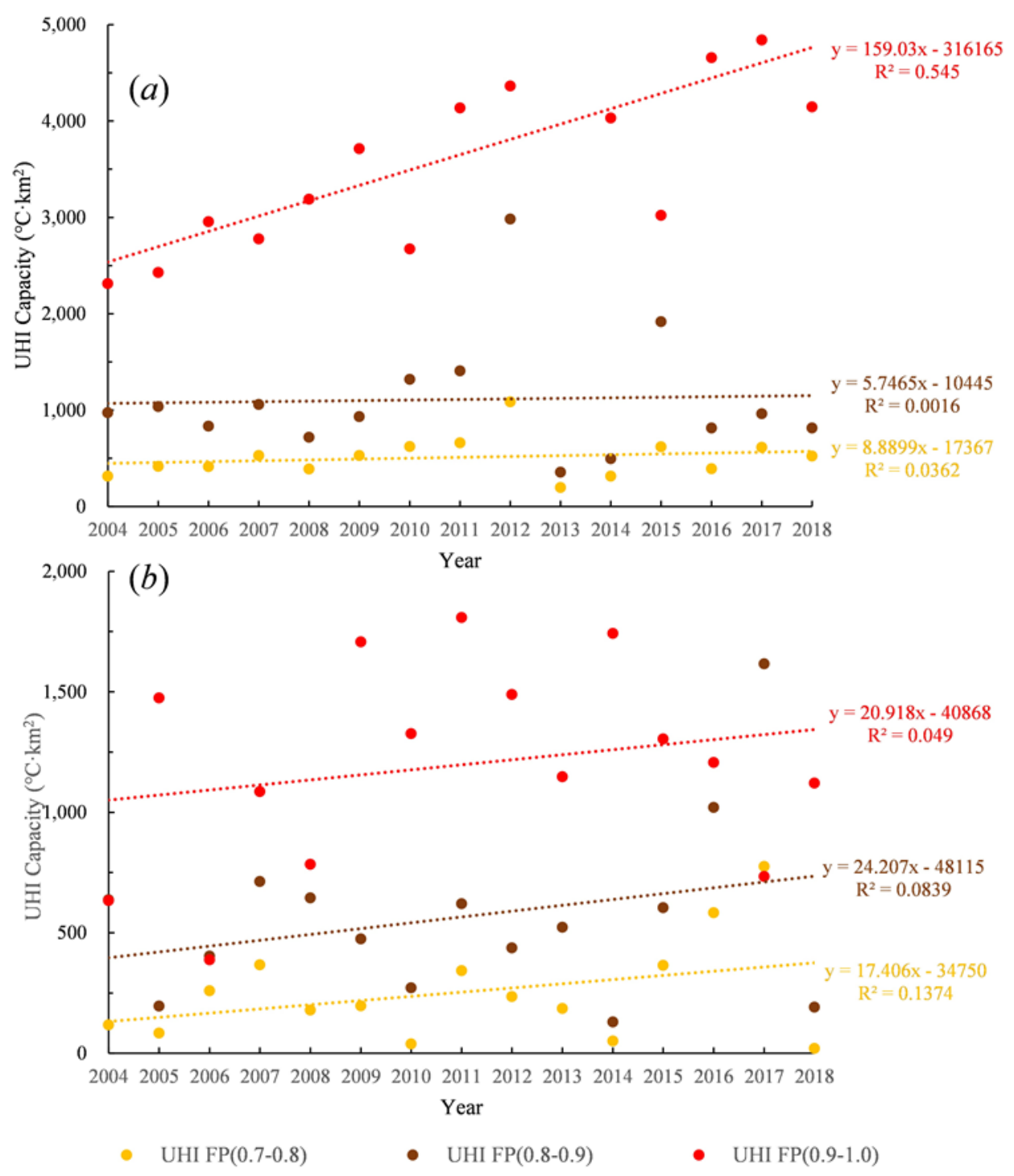

Figure 11. Temporal changes in UHI capacities of high-probability SUHI FPs between 2004 and 2018.

(a) daytime, (b) nighttime.

\section{Discussion}

\subsection{Elimination of Artificial Bias in Background Temperatures}

With rapid economic development and population flow [64,65], many places in the world are experiencing rapid urbanization [66], catalyzing the formation of the urban heat island (UHI) [3]. To capture the UHI FP is of critical importance in understanding the process of urbanization and promoting sustainable urban development. In this study, we developed a new method for determining the SUHI FP. SUHI parameters have been calculated in previous studies using a variety of mathematical approaches, including the exponential decay and Gaussian function methods [17,44-47]. These approaches are generally limited by the method used of identifying the reference rural region, which uses the urban built-up area as a core to develop buffers outward toward rural regions [17]. These methods tend to use the shape of the city as the default shape of the SUHI FP. However, there is no consistent spatial relationship between these two shapes due to the impacts of topography and landscape heterogeneity on the LST. Other methods typically choose specific points or land use types as reference rural regions to calculate the UHII [42]. These methods ignore variation in LST attenuation in different directions. The UHII can change due to randomness and contingency among the reference 
objects. Furthermore, the reference rural regions can be subject to land use and land cover change through time [67], giving rise to further uncertainties. Therefore, determining the LST threshold in the reference rural region in each direction is key to determining the SUHI FP for a metropolitan region. In this study, we applied the polar coordinate system to determine different LST thresholds for each direction, which no longer needs to consider the shape of the city in the model.

\subsection{Enhanced Reliability of Remote Sensing Data and Surface Attribute}

Previous methods have had drawbacks in determining the spatiotemporal characteristics of SUHI effects using remote sensing data. Differences among the SUHI characteristics determined in this study, including maximum and reference LST values and SUHI intensity, on different dates within the same season also demonstrate the instability of remote sensing data. Therefore, if only single-phase remote sensing images or seasonal average LST data are used to study the UHII, it would lead to the uncertainty of quantifying SUHI FP and UHII in the study [35]. Besides the application of remote sensing data, we usually ignored much other information from the surface itself including walls, facets, and windows. Since the surface temperature is extremely sensitive to different properties (geometric, radiative, thermal, moisture and aerodynamic, etc.) that can change over time (day and night, season, and year) or under certain weather conditions, the SUHI is not static in terms of time or space. Considering these uncertainties resulting from remote sensing data and surface properties, we do not propose an absolute SUHI FP, but rather the application of pixel statistical probabilities to determine SUHI FPs.

\subsection{Relationship Between SUHI FP and UHII}

The average summer maximum UHII was $4.27 \pm 0.52{ }^{\circ} \mathrm{C}$ and $3.04 \pm 0.23^{\circ} \mathrm{C}$ in the daytime and nighttime between 2004 and 2018, respectively. The Mann-Kendall Test confirmed that the upward trend (Sen's slopes is 0.5048) did not pass the 90\% significance test during the daytime. Although the upward trend did pass the $99 \%$ significance test during the nighttime, the upward trend with the Sen's slopes value of 0.0286 was very slight. However, although there was no significant increase in maximum UHII, why was the SUHI FP getting larger between 2004 and 2018? The maximum UHII results were determined from the temperature difference between the maximum temperature in urban area and the threshold temperature in reference rural regions since these are essentially areas unaffected by the urban area. The reference rural region calculated by the logistic model means that the region should remain a long-term stable temperature background field for the city. This means that the location of the area affected by the city may change, but the temperature threshold for determining whether it is affected by the city does not significantly change. According to the algorithm of deriving the UHI FP, the UHI FP and the reference rural regions are all dynamically changing. Theoretically, the UHII of each pixel in the UHI FP can be calculated, but such dynamic references make the calculated UHII less meaningful than the UHI FP itself as well as the UHI capacity. Therefore, it is more important to use the logistic model to quantitatively calculate the temperature threshold of the reference rural region to accurately delineate the boundaries of the UHI FP. Both the UHI FP and the UHI capacity are increasing resulting from these areas transforming from non-SUHI FP areas to SUHI FP that are mainly derived from urbanization, i.e., natural surfaces are being replaced by urban structures (buildings, impervious surfaces).

\section{Conclusions}

We developed a logistic method to determine the spatiotemporal evolution of SUHI FPs and calculate the UHII in the Beijing metropolitan region during the summers of 2004-2018 using MODIS 8-day L3 LST global products. The logistic model well represented the trend of LST attenuation from the urban center to the surrounding rural regions. The key transition point, calculated using the rate of change in the curvature of the fitted logistic model, represented the LST threshold in reference rural regions, and was used to further determine the SUHI FP in the study area. To avoid the influence 
of remote sensing data instability, we calculated the probability of each pixel as part of the SUHI FP. The proposed method is relatively advantageous in that it minimizes the effects of the city's shape, topography, or landscape heterogeneity. Our results also show that low-probability SUHI FPs had the largest area, followed by medium-probability and high-probability FPs. However, high-probability SUHI FPs increased significantly during the study period. The area of daytime high-probability SUHI FPs was larger than that in the nighttime. The daytime SUHI maximum intensity was higher than that during the night. However, the trend fluctuated, with no regular increase or decrease during either period.

If the rays can be used to fully represent the buffer rings from the urban center to the surrounding rural region in all directions in future studies, then the accuracy of SUHI FP identification may be further improved. Improving the accuracy of remote sensing data remains another issue for future study.

This research can be extended to different cities to automatically identify their SUHI FP and calculate UHII. More importantly, this algorithm can accurately draw the boundaries of SUHI FP for different UHII $\left(1.5^{\circ} \mathrm{C}\right.$ or $2.0^{\circ} \mathrm{C}$, etc.). It is of great significance to study urban climate and its mitigation measures in the context of global change. In addition, as the urban heat island footprint boundary is confirmed, the results can be applied in the field of urban planning. Urban planning aims at optimizing the allocation of land use in the urban region by scientific designing for new urban development land and ecological protection zone $[68,69]$, which would directly affect the urban climate. Therefore, the scope of the SUHI FP provides a spatial decision reference for urban planning.

Supplementary Materials: The following are available online at http://www.mdpi.com/2072-4292/11/11/1368/s1, Table S1: Cross Classification Table for the probability level of SUHI FPs estimated by the Gaussian surface model and the logistic model in daytime (Unit: $\mathrm{km}^{2}$ ), Table S2: Cross Classification Table for the probability level of SUHI FPs estimated by the Gaussian surface model and the logistic model in nighttime (Unit: $\mathrm{km}^{2}$ ), Table S3: Overlay analysis of land use and SUHI FP estimated by the logistic model in the daytime (Unit: $\mathrm{km}^{2}$ ), Table S4: Overlay analysis of land use and SUHI FP estimated by the Gaussian surface model in the daytime (Unit: $\left.\mathrm{km}^{2}\right)$, Table S5: Overlay analysis of land use and SUHI FP estimated by the logistic algorithm at night $\left(\mathrm{Unit}^{\mathrm{k}} \mathrm{km}^{2}\right)$, Table S6: Overlay analysis of land use and SUHI FP estimated by the Gaussian surface model at night $\left(\mathrm{Unit} \mathrm{km}^{2}\right)$.

Author Contributions: Conceptualization, Z.Q. and L.L.; methodology, Z.Q. and L.L.; software, X.X.; resources, X.X.; data curation, C.W., D.Z., J.Y., L.F., and Z.S.; visualization, Z.Q.; writing一 original draft preparation, Z.Q., C.W., and L.L.; writing-review and editing, Z.Q., L.F., and L.L.

Funding: This research was funded by National Natural Science Foundation of China (Grant \#: 41501472, 41771446), Natural Science Foundation of Tianjin City (Grant \#: 16JCQNJC08900), and the China Scholarship Council for 1 year's study at Boston University, Strategic Priority Research Program of Chinese Academy of Sciences (XDA20010302).

Acknowledgments: We thank Dan Li for his comments on formula derivation and mathematical statistics, and the discussion about data processing with Qi Zhang.

Conflicts of Interest: The authors declare no conflict of interest.

\section{References}

1. Oke, T.R. The energetic basis of the urban heat island. Q. J. R. Meteorol. Soc. 1982, 108, 1-24. [CrossRef]

2. Yang, J.; Guo, A.D.; Li, Y.H.; Zhang, Y.Q.; Li, X.M. Simulation of landscape spatial layout evolution in rural-urban fringe areas: A case study of Ganjingzi District. GISci. Remote Sens. 2019, 56, 388-405. [CrossRef]

3. Zhao, M.; Cai, H.; Qiao, Z.; Xu, X. Influence of urban expansion on the urban heat island effect in Shanghai. Int. J. Geogr. Inf. Sci. 2016, 30, 2421-2441. [CrossRef]

4. Arnfield, A.J. Two decades of urban climate research: A review of turbulence, exchanges of energy and water, and the urban heat island. Int. J. Clim. 2003, 23, 1-26. [CrossRef]

5. Oke, T.R. The urban energy balance. Prog. Phys. Geogr. Earth Env. 1988, 12, 471-508. [CrossRef]

6. Rizwan, A.M.; Dennis, L.Y.C.; Liu, C. A review on the generation, determination and mitigation of urban heat island. J. Env. Sci. 2008, 20, 120-128. [CrossRef]

7. Zhao, L.; Lee, X.; Smith, R.B.; Oleson, K. Strong contributions of local background climate to urban heat islands. Nature 2014, 511, 216-219. [CrossRef] 
8. Clinton, N.; Gong, P. Modis detected surface urban heat islands and sinks: Global locations and controls. Remote Sens. Env. 2013, 134, 294-304. [CrossRef]

9. Li, X.; Zhou, Y.; Asrar, G.R.; Imhoff, M.; Li, X. The surface urban heat island response to urban expansion: A panel analysis for the conterminous United States. Sci. Total Env. 2017, 605, 426-435. [CrossRef]

10. Liao, W.L.; Liu, X.P.; Wang, D.G.; Sheng, Y.L. The impact of energy consumption on the surface urban heat island in China's 32 major cities. Remote Sens. 2017, 9, 250. [CrossRef]

11. Peng, S.; Piao, S.; Ciais, P.; Friedlingstein, P.; Ottle, C.; Breon, F.-M.; Nan, H.; Zhou, L.; Myneni, R.B. Surface urban heat island across 419 global big cities. Env. Sci. Technol. 2012, 46, 696-703. [CrossRef] [PubMed]

12. Zhou, D.; Zhao, S.; Liu, S.; Zhang, L.; Zhu, C. Surface urban heat island in China's 32 major cities: Spatial patterns and drivers. Remote Sens. Env. 2014, 152, 51-61. [CrossRef]

13. Oke, T.R.; Mills, G.; Voogt, J.A. Urban Climates; Cambridge University Press: Cambridge, UK, 2017.

14. Cui, Y.; Xu, X.; Dong, J.; Qin, Y. Influence of urbanization factors on surface urban heat island intensity: A comparison of countries at different developmental phases. Sustainability 2016, 8, 706. [CrossRef]

15. Imhoff, M.L.; Zhang, P.; Wolfe, R.E.; Bounoua, L. Remote sensing of the urban heat island effect across biomes in the continental USA. Remote Sens. Env. 2010, 114, 504-513. [CrossRef]

16. Qiao, Z.; Tian, G.; Zhang, L.; Xu, X. Influences of urban expansion on urban heat island in Beijing during 1989-2010. Adv. Meteorol. 2014, 2014, 1-11. [CrossRef]

17. Zhou, D.; Zhao, S.; Zhang, L.; Sun, G.; Liu, Y. The footprint of urban heat island effect in China. Sci. Rep. 2015, 5, 11160. [CrossRef]

18. Chen, W.; Zhang, Y.; Peng, C.; Gao, W. Evaluation of urbanization dynamics and its impacts on surface heat islands: A case study of Beijing, China. Remote Sens. 2017, 9, 453. [CrossRef]

19. Qiao, Z.; Xu, X.; Wu, F.; Luo, W.; Wang, F.; Liu, L.; Sun, Z. Urban ventilation network model: A case study of the core zone of capital function in Beijing metropolitan area. J. Clean. Prod. 2017, 168, 526-535. [CrossRef]

20. Qiao, Z.; Wu, C.; Huang, N.; Xu, X.; Sun, Z.; Sun, X. Spatio-temporal structure of the urban thermal environment in Beijing based on an empirical orthogonal function. J. Spat. Sci. 2018, 63, 297-310. [CrossRef]

21. Qiao, Z.; Zhang, D.; Xu, X.; Liu, L. Robustness of satellite-derived land surface parameters to urban land surface temperature. Int. J. Remote Sens. 2019, 40, 1858-1874. [CrossRef]

22. Yang, J.; Su, J.R.; Xia, J.H.; Jin, C.; Li, X.M.; Ge, Q.S. The impact of spatial form of urban architecture on the urban thermal environment: A case study of the Zhongshan district, Dalian, China. IEEE J. Sel. Top. Appl. Earth Obs. Remote Sens. 2018, 11, 2709-2716. [CrossRef]

23. Yang, J.; Jin, S.H.; Xiao, X.M.; Jin, C.; Xia, J.H.; Li, X.M.; Wang, S.J. Local climate zone ventilation and urban land surface temperatures: Towards a performance-based and wind-sensitive planning proposal in megacities. Sustain. Cities Soc. 2019, 47, 1-11. [CrossRef]

24. Zhou, D.C.; Xiao, J.F.; Bonafoni, S.; Berger, C.; Deilami, K.; Zhou, Y.Y.; Frolking, S.; Yao, R.; Qiao, Z.; Sobrino, J.A. Satellite remote sensing of surface urban heat islands: Progress, challenges, and perspectives. Remote Sens. 2019, 11, 48. [CrossRef]

25. Lai, J.; Zhan, W.; Huang, F.; Quan, J.; Hu, L.; Gao, L.; Ju, W. Does quality control matter? Surface urban heat island intensity variations estimated by satellite-derived land surface temperature products. ISPRS J. Photogramm. Remote Sens. 2018, 139, 212-227. [CrossRef]

26. Li, H.; Zhou, Y.; Li, X.; Meng, L.; Wang, X.; Wu, S.; Sodoudi, S. A new method to quantify surface urban heat island intensity. Sci. Total Environ. 2018, 624, 262-272. [CrossRef] [PubMed]

27. Gawuc, L.; Struzewska, J. Impact of MODIS quality control on temporally aggregated urban surface temperature and long-term surface urban heat island intensity. Remote Sens. 2016, 8, 374. [CrossRef]

28. Memon, R.A.; Leung, D.Y.; Liu, C.H. An investigation of urban heat island intensity (UHII) as an indicator of urban heating. Atmos. Res. 2009, 94, 491-500. [CrossRef]

29. Wang, J.; Huang, B.; Fu, D.; Atkinson, P.M. Spatiotemporal variation in surface urban heat island intensity and associated determinants across major Chinese Cities. Remote Sens. 2015, 7, 3670-3689. [CrossRef]

30. Yao, R.; Wang, L.; Huang, X.; Niu, Y.; Chen, Y.; Niu, Z. The influence of different data and method on estimating the surface urban heat island intensity. Ecol. Indic. 2018, 89, 45-55. [CrossRef]

31. Zhao, S.; Zhou, D.; Liu, S. Data concurrency is required for estimating urban heat island intensity. Env. Pollut. 2016, 208, 118-124. [CrossRef] 
32. Zhou, B.; Rybski, D.; Kropp, J.P. On the statistics of urban heat island intensity. Geophys. Res. Lett. 2013, 40, $5486-5491$. [CrossRef]

33. Chen, X.L.; Zhao, H.M.; Li, P.X.; Yin, Z.Y. Remote sensing image-based analysis of the relationship between urban heat island and land use/cover changes. Remote Sens. Env. 2006, 104, 133-146. [CrossRef]

34. Li, W.; Cao, Q.; Lang, K.; Wu, J. Linking potential heat source and sink to urban heat island: Heterogeneous effects of landscape pattern on land surface temperature. Sci. Total Env. 2017, 586, 457-465. [CrossRef] [PubMed]

35. Qiao, Z.; Tian, G.; Xiao, L. Diurnal and seasonal impacts of urbanization on the urban thermal environment: A case study of Beijing using MODIS data. ISPRS J. Photogramm. Remote Sens. 2013, 85, 93-101. [CrossRef]

36. Bohnenstengel, S.I.; Evans, S.; Clark, P.A.; Belcher, S.E. Simulations of the London urban heat island. Q. J. R. Meteorol. Soc. 2011, 137, 1625-1640. [CrossRef]

37. Renard, F.; Alonso, L.; Fitts, Y.; Hadjiosif, A.; Comby, J. Evaluation of the effect of urban redevelopment on surface urban heat islands. Remote Sens. 2019, 11, 299. [CrossRef]

38. Sobrino, J.A.; Oltra-Carrió, R.; Sòria, G.; Jiménez-Muñoz, J.C.; Franch, B.; Hidalgo, V.; Mattar, C.; Julien, Y.; Cuenca, J.; Romaguera, M.; et al. Evaluation of the surface urban heat island effect in the city of Madrid by thermal remote sensing. Int. J. Remote Sens. 2013, 34, 3177-3192. [CrossRef]

39. Chen, F.; Liu, J.; Ge, Q. Pulling vs. pushing: effect of climate factors on periodical fluctuation of Russian and South Korean tourist demand in Hainan Island, China. Chin. Geogr. Sci. 2017, 27, 648-659. [CrossRef]

40. Martin, P.; Baudouin, Y.; Gachon, P. An alternative method to characterize the surface urban heat island. Int. J. Biometeorol. 2015, 59, 849-861. [CrossRef]

41. Azevedo, J.A.; Chapman, L.; Muller, C.L. Quantifying the daytime and night-time urban heat island in Birmingham, UK: A comparison of satellite derived land surface temperature and high resolution air temperature observations. Remote Sens. 2016, 8, 153. [CrossRef]

42. Wang, K.; Wang, J.; Wang, P.; Sparrow, M.; Yang, J.; Chen, H. Influences of urbanization on surface characteristics as derived from the Moderate-Resolution Imaging Spectroradiometer: A case study for the Beijing metropolitan area. J. Geophys. Res. Atmos. 2007, 112, D22S06. [CrossRef]

43. Wang, K.; Jiang, S.; Wang, J.; Zhou, C.; Wang, X.; Lee, X. Comparing the diurnal and seasonal variabilities of atmospheric and surface urban heat islands based on the Beijing urban meteorological network. J. Geophys. Res. Atmos. 2017, 122, 2131-2154. [CrossRef]

44. Jin, M.L.; Dickinson, R.E.; Zhang, D.L. The footprint of urban areas on global climate as characterized by MODIS. J. Clim. 2005, 18, 1551-1565. [CrossRef]

45. Santamouris, M.; Paraponiaris, K.; Mihalakakou, G. Estimating the ecological footprint of the heat island effect over Athens, Greece. Clim. Change 2007, 80, 265-276. [CrossRef]

46. Yang, Q.; Huang, X.; Tang, Q. The footprint of urban heat island effect in 302 Chinese cities: Temporal trends and associated factors. Sci. Total Env. 2019, 655, 652-662. [CrossRef] [PubMed]

47. Zhang, X.; Friedl, M.A.; Schaaf, C.B.; Strahler, A.H.; Schneider, A. The footprint of urban climates on vegetation phenology. Geophys. Res. Lett. 2004, 31, L12209. [CrossRef]

48. Keeratikasikorn, C.; Bonafoni, S. Satellite images and Gaussian parameterization for an extensive analysis of urban heat islands in Thailand. Remote Sens. 2018, 10, 665. [CrossRef]

49. Quan, J.; Chen, Y.; Zhan, W.; Wang, J.; Voogt, J.; Wang, M. Multi-temporal trajectory of the urban heat island centroid in Beijing, China based on a gaussian volume model. Remote Sens. Environ. 2014, 149, $33-46$. [CrossRef]

50. Streutker, D.R. A remote sensing study of the urban heat island of Houston, Texas. Int. J. Remote Sens. 2002, 23, 2595-2608. [CrossRef]

51. Yang, J.; Sun, J.; Ge, Q.S.; Li, X.M. Assessing the Impacts of Urbanization-Associated Green Space on Urban Land Surface Temperature: A Case Study of Dalian, China. Urban For. Urban Green. 2017, 22, 1-10. [CrossRef]

52. Sun, R.; Chen, L. How can urban water bodies be designed for climate adaptation? Landsc. Urban Plan. 2012, 105, 27-33. [CrossRef]

53. Sun, R.; Xie, W.; Chen, L. A landscape connectivity model to quantify contributions of heat sources and sinks in urban regions. Landsc. Urban Plan. 2018, 178, 43-50. [CrossRef]

54. Xu, X.; Cai, H.; Qiao, Z.; Wang, L.; Jin, C.; Ge, Y.N.; Wang, L.Y.; Xu, F.J. Impacts of park landscape structure on thermal environment using QuickBird and Landsat images. Chin. Geogr. Sci. 2017, 27, 818-826. [CrossRef] 
55. Zhou, W.; Huang, G.; Cadenasso, M.L. Does spatial configuration matter? Understanding the effects of land cover pattern on land surface temperature in urban landscapes. Landsc. Urban Plan. 2011, 102, 54-63. [CrossRef]

56. Zhou, W.; Qian, Y.; Li, X.; Li, W.; Han, L. Relationships between land cover and the surface urban heat island: Seasonal variability and effects of spatial and thematic resolution of land cover data on predicting land surface temperatures. Landsc. Ecol. 2014, 29, 153-167. [CrossRef]

57. Meng, Q.; Zhang, L.; Sun, Z.; Meng, F.; Wang, L.; Sun, Y. Characterizing spatial and temporal trends of surface urban heat island effect in an urban main built-up area: A 12-year case study in Beijing, China. Remote Sens. Environ. 2018, 204, 826-837. [CrossRef]

58. Liu, J.; Cheng, H.; Jiang, D.; Huang, L. Impact of climate-related changes to the timing of autumn foliage colouration on tourism in Japan. Tourism Manage. 2019, 70, 262-272. [CrossRef]

59. Liu, J.Y.; Liu, M.L.; Tian, H.Q. Spatial and temporal patterns of China's cropland during 1990-2000: An analysis based on Landsat TM data. Remote Sens. Env. 2005, 98, 442-456. [CrossRef]

60. Gong, P.; Liu, H.; Zhang, M.; Li, C.; Wang, J.; Huang, H.; Clinton, N.; Ji, L.; Li, W.; Bai, Y.; et al. Stable classification with limited sample: Transferring a 30-m resolution sample set collected in 2015 to mapping 10-m resolution global land cover in 2017. Sci. Bull. 2019, 64, 370-373. [CrossRef]

61. Feng, L.; Guo, S.; Zhu, L.J.; Zhou, Y.N.; Lu, D. Urban vegetation phenology analysis using high spatio-temporal NDVI time series. Urban For. Urban Green. 2017, 25, 43-57. [CrossRef]

62. Villegas, D.; Aparicio, N.; Blanco, R.; Royo, C. Biomass accumulation and main stem elongation of durum wheat grown under Mediterranean conditions. Ann. Bot. 2001, 88, 617-627. [CrossRef]

63. Zhang, X.; Friedl, M.A.; Schaaf, C.B.; Strahler, A.H.; Hodges, J.C.; Gao, F.; Reed, B.C.; Huete, A. Monitoring vegetation phenology using MODIS. Remote Sens. Env. 2003, 84, 471-475. [CrossRef]

64. Zhang, Q.; Bilsborrow, R.E.; Song, C.; Tao, S.; Huang, Q. Determinants of out-migration in rural China: Effects of payments for ecosystem services. Popul. Environ. 2018, 40, 182-203. [CrossRef]

65. Zhang, Q.; Bilsborrow, R.E.; Song, C.; Tao, S.; Huang, Q. Rural household income distribution and inequality in China: Effects of payments for ecosystem services policies and other factors. Ecol. Econ. 2019, 160, 114-127. [CrossRef]

66. Liu, C.; Zhang, Q.; Luo, H.; Qi, S.; Tao, S.; Xu, H.; Yao, Y. An efficient approach to capture continuous impervious surface dynamics using spatial-temporal rules and dense Landsat time series stacks. Remote Sens. Env. 2019, 229, 114-132. [CrossRef]

67. Zhang, Q.; Song, C.; Chen, X. Effects of China's payment for ecosystem services programs on cropland abandonment: A case study in Tiantangzhai Township, Anhui, China. Land Use Policy 2018, 73, 239-248. [CrossRef]

68. Wang, Y.; Li, X.; Zhang, Q.; Li, J.; Zhou, X. Projections of future land use changes: Multiple scenarios-based impacts analysis on ecosystem services for Wuhan city, China. Ecol. Indic. 2018, 94, 430-445. [CrossRef]

69. Liu, J.; Wang, J.; Wang, S.; Wang, J.; Deng, G. Analysis and simulation of the spatiotemporal evolution pattern of tourism lands at the Natural World Heritage Site Jiuzhaigou, China. Habitat Int. 2018, 79, 74-88. [CrossRef]

(C) 2019 by the authors. Licensee MDPI, Basel, Switzerland. This article is an open access article distributed under the terms and conditions of the Creative Commons Attribution (CC BY) license (http://creativecommons.org/licenses/by/4.0/). 